\title{
Opinião e cenários comunicativos: influência de fatores contextuais nos processos sociopsicológicos da espiral do silêncio
}

Junia Ortiz ${ }^{1}$ (i)

\begin{abstract}
Este artigo tem como objetivo investigar como fatores contextuais podem afetar os processos sociopsicológicos especificados pela teoria da espiral do silêncio, como o medo de isolamento e a congruência de opinião. Os contextos para este artigo foram divididos em ambientes on-line - sites de redes sociais, salas de bate-papo e fóruns de discussão on-line - e comunicação face a face. Os dados foram obtidos a partir da aplicação de questionários on-line sobre a opinião a respeito da união civil entre pessoas do mesmo sexo. Com um total de 226 formulários preenchidos, os dados coletados receberam tratamento estatístico para a realização do teste das hipóteses. A análise dos dados demonstrou que a expressão da opinião está ligada a fatores que se relacionam com as características específicas de cada meio/ambiente em que a opinião é expressa, em conjunto com os fatores sociopsicológicos que operam na espiral do silêncio. Ou seja, a configuração da comunicação afeta o desejo dos indivíduos em expressar seus pontos de vista, fazendo com que a espiral do silêncio aconteça de forma diferente em cada contexto específico.
\end{abstract}

Palavras-chave: opinião; espiral do silêncio; comunicação mediada por computador; união civil homossexual; contextos comunicativos

\section{Introdução}

Este artigo tem como propósito investigar como fatores contextuais podem afetar o modo como as pessoas expressam suas opiniões em diferentes ambientes. A teoria da espiral do silêncio (Noelle-Neumann, 1974) é aqui o ponto de partida para pensar a expressão da opinião. De acordo com a teoria, determinados temas, principalmente aqueles de grande abrangência social e com opiniões divergentes na esfera pública, tendem a desencadear uma série de fatores sociopsicológicos nos indivíduos, que passam a avaliar as possíveis consequências da expressão de uma opinião.

A base da teoria está em dividir a percepção das opiniões como majoritárias e minoritárias. Assim, de forma geral, se um indivíduo percebe que sua opinião não está de acordo com a opinião que considera ser a da maioria em dado ambiente social, tende a se silenciar como forma de evitar consequências negativas para si. Esse processo gera,

\footnotetext{
1 Universidade Federal da Bahia, Programa de Pós-graduação em Comunicação e Cultura Contemporâneas. Salvador (BA), Brasil. E-mail: <junia.ortiz@gmail.com>.
} 
então, uma espiral em que opiniões consideradas como minoritárias tendem a ser silenciadas e opiniões percebidas como majoritárias se tornam cada vez mais dominantes.

Entendendo que os pressupostos basilares da espiral do silêncio possuem fundamentação empírica (Lin e Pfau, 2001; Neuwirth, Frederik e Mayo, 2007; Scheufele, Shanahan e Lee, 2001), este artigo se propõe a avaliar o impacto que os canais em que a comunicação acontece podem oferecer a esses pressupostos, além de considerar o contexto social que envolve o tema sobre o qual se expressa uma opinião. Nessa linha, propõe-se avaliar como a suscetibilidade de um indivíduo expressar a opinião pessoal pode variar de acordo com o grau de presença social nos cenários comunicativos. Os contextos foram divididos em ambientes on-line - sites de redes sociais, salas de batepapo e fóruns de discussão on-line - e comunicação face a face, nos quais foi medida a percepção dos indivíduos com relação à exposição da imagem pessoal. Para tanto, foram aplicados questionários on-line a respeito da expressão da opinião sobre a união civil entre pessoas do mesmo sexo, com um total de 226 formulários preenchidos.

Partindo dessa perspectiva, pretende-se avaliar a extensão na qual os contextos comunicativos afetam a vontade dos indivíduos em expressar suas opiniões, moderando os efeitos dos fatores sociopsicológicos que operam na espiral do silêncio.

\section{Espiral do silêncio: origens da teoria}

Postulados a partir das pesquisas da alemã Elisabeth Noelle-Neumann na década de 1970, os pressupostos teóricos da espiral do silêncio podem ser divididos em três níveis: individual, sistema midiático e social (Lin e Pfau, 2001). No primeiro nível, os indivíduos têm medo de serem isolados de seus pares e, com o objetivo de evitar esse isolamento ou a perda de popularidade, observam constantemente o ambiente social a fim de localizar quais são as posições adequadas. Com relação a alguns temas, a respeito dos quais as opiniões estão em disputa ou ainda são inconstantes, os indivíduos tentam descobrir em qual lado podem se expressar sem perder a popularidade. De acordo com a teoria, aqueles que notam que suas opiniões pessoais são propagadas e apoiadas por outros irão exprimir suas opiniões confiantemente em público, no entanto, os que acreditam que suas opiniões não são compartilhadas pela maioria ou que estão perdendo terreno irão adotar uma atitude mais reservada quando falar em público ou até mesmo se afastar da discussão pública. Isso conduz a um processo em espiral no qual a minoria percebida se torna cada vez menos suscetível a se expressar e o grupo majoritário passa a ser dominante (Lin e Pfau, 2001; Neuwirth, Frederik e Mayo, 2007; Scheufele, Shanahan e Lee, 2001).

A relação dos meios de comunicação com a teoria se estabelece na medida em que se entende que os media podem afetar o processo de espiral do silêncio. Isso pode acontecer de três formas: os media configuram impressões sobre quais opiniões são dominantes; configuram impressões sobre quais opiniões estão em crescimento e quais 
não estão; e configuram impressões sobre quais opiniões individuais podem ser articuladas em público sem risco de isolamento (Lin e Pfau, 2001). Dessa forma, muitos autores destacam a existência de uma conexão entre a espiral do silêncio e a hipótese da agenda setting (e.g., Petrič e Pinter, 2002; Neuwirth, 2000; Scheufele e Moy, 2000), proposta por McCombs e Shaw em 1972. O agendamento se caracteriza como um procedimento de seleção das temáticas disponíveis para a conversação pública em nossa sociedade, a hipótese está relacionada a forma e seleção de conteúdos e temas apresentados pela mídia e, sobretudo, às percepções proporcionadas a partir desse estabelecimento. Nessa linha, o argumento parte da ideia de que os meios de comunicação de massa definem a agenda de discussão pública e estabelecem as prioridades das agendas públicas por ditar quais problemas a sociedade deve considerar urgente. Além disso, os media transmitem informações sobre o clima de opinião a respeito de questões específicas. Nesse sentido, muitos estudos têm demonstrado que a utilização dos meios noticiosos está positivamente relacionada ao desejo de se expressar (e.g., Eveland, McLeod e Sgnorielli, 1995; Binder et al., 2009; Baldassare e Katz, 1996; Moy, Domke e Stamm, 2001; Neuwirth, Frederik e Mayo, 2007; Pan et al., 2006; Scheufele, 1999).

Em uma perspectiva social, a teoria propõe que o medo de isolamento leva os indivíduos a examinar o meio ambiente social para avaliar o clima de opinião, analisando a distribuição de opiniões contra e a favor de suas próprias ideias (Noelle-Neumann, 1974 , p. 44). Assim, ao tentar evitar o isolamento, os indivíduos procuram se adequar à corrente compreendida como principal, a partir de sua percepção individual da opinião pública. Indivíduos que percebem que suas opiniões são populares ou ganham apoio público estarão mais suscetíveis a expressar seus pontos de vista, ao contrário daqueles que acreditam que suas opiniões não são compartilhadas pela maioria. De forma geral, as pesquisas envolvendo a área de media effects sugerem diferentes possibilidades de avaliação do clima de opinião. Em primeiro lugar, temos os estudos que propõem que o clima de opinião é percebido a partir das representações da mídia, que, além de pautar os temas para a discussão pública, configuram impressões sobre quais opiniões são dominantes, como dito anteriormente (Lin e Pfau, 2001; Neuwirth, 2000; Scheufele e Moy, 2000).

Outras pesquisas sugerem que, quando solicitadas a avaliar as opiniões de outros, as pessoas exibem um viés perceptivo conhecido como projeção ou falso consenso, isto é, a tendência de ver a própria opinião como relativamente comum enquanto opiniões alternativas são vistas como menos comuns. O mesmo fenômeno é referido, às vezes, como o "efeito do espelho", descrevendo a tendência das pessoas de ver suas visões pessoais refletidas por outros indivíduos no ambiente externo (Christen e Gunther, 2003) $)^{2}$. Esses autores realizaram um estudo com o propósito de testar o

\footnotetext{
2 A ideia da percepção da opinião pública a partir do viés de projeção é defendida, principalmente, pelos pesquisadores da hipótese do efeito de terceira pessoa (Davison, 1983), segundo a qual as pessoas tendem a superestimar a influência que a comunicação de massa tem nas atitudes e comportamentos dos
} 
fenômeno da projeção em avaliações pessoais da opinião pública. Para tanto, eles partem das explicações teóricas para o efeito desenvolvidas por Marks e Miller (1987), das quais destacamos aqui duas: processos motivacionais e processamento lógico de informação.

De acordo com os processos motivacionais, o desejo de manter a confiança, a autoestima e o apoio social pode levar indivíduos a exagerar o grau de similaridade entre eles e os outros. As pessoas frequentemente presumem maior similaridade entre sua própria visão e a visão de outros quando elas estão menos convictas da adequação e da correção de sua própria posição. Para indivíduos convictos, certos de suas posições, percepções de consenso externo tendem a ser menos importantes para reforço ou reafirmação (Gunther e Chia, 2001; Duck, Hogg e Therry, 1999; Perloff, 1999). Já a projeção a partir do processamento lógico de informação se dá pela compreensão de que as pessoas consideram que todos são afetados de forma homogênea por forças situacionais e por isso possuem as mesmas visões a respeito de determinados assuntos. Um pressuposto implícito nessa explicação é que as pessoas formam sua própria opinião baseadas no processamento da informação midiática (Christen e Gunther, 2003).

Uma terceira opção explorada por alguns autores se baseia na ideia de que as percepções da opinião pública se dão por conta de experiências pessoais anteriores, a partir do grau de envolvimento do indivíduo em uma determinada questão ou grupo social (Scheufele, Shanahan e Lee, 2001; Christen e Gunther, 2003). Quando as pessoas são bastante envolvidas em uma questão ou grupo, atitudes preexistentes e opiniões podem levá-las a avaliar uma cobertura imparcial e objetiva como sendo injustamente enviesada. As percepções da tendência hostil na cobertura da mídia podem na verdade exercer influência significativa nas percepções de opinião pública. Isso pode ocorrer, por exemplo, a partir da ideia de inferência da imprensa persuasiva, desenvolvida por Gunther (1998), segundo a qual as pessoas inferem a opinião pública a partir de sua própria avaliação da tendência da cobertura da mídia e da crença de que os outros são influenciados pela cobertura. Nessa linha, o conceito central é que as pessoas podem facilmente formar uma ideia do que outros estão pensando por inferência, a partir das informações que eles pensam que outros estão consumindo, o que pode levar a uma conclusão errônea de que a própria opinião é minoritária e conduzir ao silenciamento (Gunther e Chia, 2001).

Embora existam muitos estudos a respeito da espiral do silêncio, alguns autores têm argumentado que ela não é muito bem comprovada empiricamente, especialmente a relação entre a percepção do clima de opinião e a vontade de expressar uma opinião (Scheufele, Shanahan e Lee, 2001). Segundo Noelle-Neumann (1974), qualquer tentativa de testar a espiral do silêncio deve lidar com cinco pressupostos: (1) a sociedade ameaça os desviantes com isolamento; (2) indivíduos constantemente têm medo do isolamento; (3) o medo do isolamento leva os indivíduos a avaliar o clima de opinião; (4) os 
resultados dessa avaliação afetam o comportamento dos indivíduos em público; (5) tomados em conjunto, o processo acima é responsável pela formação, defesa e alteração da opinião pública.

\section{A espiral do silêncio na comunicação mediada por computador}

Tendo em vista os processos disfuncionais que atuam na espiral do silêncio, fazse necessário, ainda, levar em conta as influências contextuais na expressão da opinião, que podem interferir nos efeitos do potencial de coerção da maioria e na relutância da minoria em demonstrar sua opinião. Nessa linha, algumas pesquisas têm se centrado na investigação das diferenças estruturais entre os contextos da comunicação mediada por computador $(C M C)$ e da comunicação face a face $(F 2 F)$, que podem resultar em diferentes proporções de expressão de opinião entre os participantes em uma discussão (Barber, Mattson e Peterson, 1997; London, 1993; McDevitt, Kiousis e Whal-Jorgensen, 2003; Ho e McLeod, 2008).

De acordo com o sociólogo Thompson (1998), a interação face a face é aquela que acontece em condição de compartilhamento dos sistemas de referência de tempo e espaço, em um contexto de copresença dos participantes. De forma geral, esse tipo de interação tem caráter dialógico, prevendo também a possibilidade do emprego do que o autor denomina de deixas simbólicas, visto que, além da comunicação verbal, é possível a utilização de uma grande quantidade de sistemas sígnicos, como o gestual, o vestuário, o tom da voz etc. (Thompson, 1998, p. 78). Dessa forma, por conta da presença física de outros em uma comunicação $F 2 F$, os indivíduos tendem a sentir mais receio de que seus pontos de vista sejam percebidos como divergentes e, por isso, são mais relutantes em demonstrar sua opinião.

Em contraste, as interações mediadas, segundo a determinação de Thompson (1998), são aquelas que implicam a utilização de meios técnicos, tendo como característica a possibilidade de transmissão de mensagens em condições de não coincidência espacial e/ou temporal, o que diminui consideravelmente o emprego de sistemas sígnicos. Enquanto as interações $F 2 F$ dependem muito da linguagem falada e de expressões não verbais observáveis como gestos e sinais de status/posição, a interação mediada por computador pode se estabelecer através de recursos como mensagens de texto e anonimato. Esse tipo de comunicação torna certas dinâmicas sociais menos evidentes, pois se retira a ênfase das características de posicionamento e dos aspectos físicos dos grupos (Ho e McLeod, 2008).

Com o intuito de testar os processos de espiral do silêncio em discussões reais, McDevitt, Kiousis e Whal-Jorgensen (2003) realizaram uma pesquisa com o objetivo de comparar a atitude dos participantes de discussões em cenários de comunicação face a face e de discussões mediadas por computador, especificamente em salas de bate-papo on-line. Para os autores da pesquisa, no cenário da interação mediada, a predisposição dos indivíduos em expressar suas opiniões seria maior. Isso aconteceria porque, por 
conta das características do ambiente on-line, os participantes do grupo minoritário se sentiriam mais à vontade para expressar suas opiniões. Por outro lado, os participantes do grupo majoritário sentiriam menos obrigação em expressar suas opiniões e, por conta disso, a expressão da opinião seria menor. A pesquisa foi realizada com 48 estudantes, separados em grupos, para a realização de 12 sessões de discussão a respeito do aborto, 6 no contexto da comunicação face a face e 6 em salas de bate-papo on-line.

Comparados aos participantes das discussões face a face, as opiniões de ambos os grupos, maioria e minoria, foram percebidas como mais moderadas na ocasião da comunicação mediada por computador. Houve uma preferência por uma discussão neutra, não combativa. A observação dos pesquisadores demonstrou que, surpreendentemente, os participantes com opiniões minoritárias tenderam a se manifestar mais do que os de opiniões majoritárias. Os autores oferecem duas explicações para o ocorrido: para o grupo da minoria, a relativa falta de intimidação permite que os indivíduos participem ativamente; na perspectiva da maioria, os resultados sugerem que indivíduos em situação de baixa presença social talvez sintam menos motivação para participar (McDevitt, Kiousis e Whal-Jorgensen, 2003).

Em outra pesquisa, Ho e McLeod (2008) tentam avaliar a extensão na qual a comunicação modera os efeitos de fatores sociopsicológicos na expressão da opinião. Os dados para o estudo foram coletados em uma pesquisa on-line, na qual os respondentes foram designados a uma das duas condições experimentais hipotéticas: (a) cenário de comunicação face a face e (b) comunicação mediada por computador. Os participantes foram informados que haveria um segundo estágio do estudo, no qual aconteceria uma discussão a respeito da legalização do casamento entre pessoas do mesmo sexo, com a presença de outros participantes com opiniões divergentes. Então, solicitou-se que eles indicassem a porcentagem de como eles estariam suscetíveis a declarar a própria opinião nos diferentes contextos. Após todos completarem o questionário, foi enviado um e-mail para os respondentes explicando que na verdade não haveria discussão alguma. Os resultados do estudo revelaram que os respondentes demonstraram menores níveis de inclinação para expressar sua própria opinião na comunicação face a face, ao passo que os respondentes solicitados a falar na interação mediada foram, em geral, significativamente mais suscetíveis a expressar sua própria opinião. Ainda, o impacto do medo de isolamento na expressão da opinião foi atenuado pela discussão mediada por computador. Com isso, entende-se que a configuração da comunicação pode interferir no desejo dos indivíduos em expressar seus pontos de vista pessoais.

\section{Espiral do silêncio e união civil entre pessoas do mesmo sexo}

A partir da década de 1990, vários países, em todo o mundo, passaram a discutir a legalização do casamento entre pessoas do mesmo sexo. O primeiro país a legalizar a união foram os Países Baixos, no ano de 2001. No Brasil, o reconhecimento da união estável entre casais do mesmo sexo como entidade familiar aconteceu em 2011, no dia 5 
de maio, por meio de reconhecimento constitucional pelo Supremo Tribunal Federal (STF). Com isso, passam a valer para os casais do mesmo sexo as mesmas normas que regulamentam as relações estáveis entre homens e mulheres, as regras valem para todo o território nacional. A decisão do STF, no entanto, não foi bem recebida por todos os setores da sociedade, sendo alvo de críticas. Mesmo com o reconhecimento do STF, ainda há grande divergência de opinião entre os brasileiros com relação à regulamentação da união civil entre pessoas do mesmo sexo.

Entre os dias 14 e 18 de julho de 2011, uma pesquisa realizada pelo Instituto Brasileiro de Opinião Pública e Estatística (Ibope Inteligência) revelou que uma maioria de $55 \%$ dos brasileiros era contrária à decisão do $\mathrm{STF}^{3}$. De acordo com os resultados da pesquisa, $52 \%$ das mulheres eram a favor enquanto $63 \%$ dos homens eram contra. Entre os jovens de 16 a 24 anos, $60 \%$ eram favoráveis. Entre os mais velhos, com 50 anos ou mais, apenas $27 \%$ concordavam com a decisão. De acordo com a pesquisa realizada pelo Ibope, a aceitação do casamento entre pessoas do mesmo sexo tendia a ser maior quanto maior a escolaridade e, além disso, ainda variava de acordo com a religião, com maior apoio entre os espíritas e adeptos de religiões não cristãs.

Dois anos depois, em 16 de maio de 2013, passou a vigorar a Resolução no 175, aprovada pelo Conselho Nacional de Justiça (CNJ). A partir dessa data, cartórios de todo - Brasil passaram a ser impedidos de recusar a realização de casamentos civis entre pessoas do mesmo sexo, os cartórios também foram impedidos de deixar de converter em casamento a união estável homoafetiva ${ }^{4}$. Em 2016, registrou-se um aumento de $51,7 \%$ das uniões civis entre pessoas do mesmo sexo, referente ao comparativo entre os anos 2014 e 2015, de acordo com a pesquisa "Estatísticas do Registro Civil 2015", divulgada pelo Instituto Brasileiro de Geografia e Estatística (IBGE) ${ }^{5}$. Ainda assim, uma pesquisa realizada pela agência Hello Research, com resultados divulgados em 2015, revelou que $49 \%$ dos entrevistados em 70 diferentes cidades brasileiras eram contra a união civil entre pessoas do mesmo sexo, $30 \%$ eram totalmente a favor e $21 \%$ eram indiferentes ${ }^{6}$. Mesmo considerando as diferenças metodológicas entre os dois institutos de pesquisa aqui citados, há que se pontuar um indicativo de diminuição no percentual de brasileiros contrários ao casamento homoafetivo: em 2011, o Ibope registrou 55\% de brasileiros contrários à decisão do STF de reconhecimento da união estável entre casais

3 Ver: "Ibope: $55 \%$ da população é contra união civil gay". Disponível em: <http://revistaepoca.globo.com/Revista/Epoca/0,,EMI252815-15228,00IBOPE+DA+POPULACAO+E+CONTRA+UNIAO+CIVIL+GAY.html >. Acesso em: 10 jun. 2018.

4 Ver: "Resolução sobre casamento civil entre pessoas do mesmo sexo é aprovada pelo Conselho Nacional de Justiça". Disponível em: <http://www2.stf.jus.br/portalStfInternacional/cms/destaquesNewsletter.php?sigla=newsletterPortalIntern acionalDestaques\&idConteudo $=238515>$. Acesso em: 10 jun. 2018.

5 Ver: "Casamento gay aumenta 51,7\% desde que foi legalizado em 2013". Disponível em: <https://exame.abril.com.br/brasil/casamento-gay-aumenta-517-desde-que-foi-legalizado-em-2013/>. Acesso em: 10 jun. 2018.

6 Ver: "Quase metade dos brasileiros é contra casamento gay". Disponível em: <https://exame.abril.com.br/brasil/quase-50-dos-brasileiros-sao-contra-casamentos-gays/>. Acesso em: 10 jun. 2018. 
do mesmo sexo. No entanto, mesmo com os avanços no marco legal, não se pode deixar de destacar que esta não é uma questão consensual na sociedade brasileira.

Levando em consideração todas essas questões que dizem respeito à união civil entre pessoas do mesmo sexo, o tema se mostra como objeto viável para o estudo proposto, visto que a natureza do assunto é fundamental para a ocorrência da espiral do silêncio. Assim, a escolha do tema para este artigo se justifica por ser um assunto que tem permanecido na agenda pública brasileira como uma questão que divide opiniões, envolvendo aspectos morais e jurídicos, com visibilidade na sociedade brasileira atual. Além disso, vários estudos anteriores sobre a espiral do silêncio têm empregado variações dessa questão a fim de examinar o grau de expressão da opinião (Ho e McLeod, 2008; Hayes, Shanahan e Glynn, 2001; Willnat, Lee e Detenber, 2002).

\section{A pesquisa}

Os dados para a realização deste artigo foram obtidos a partir da aplicação de questionários on-line. O método de composição da amostra foi não probabilístico e por adesão voluntária (Levin e Fox, 2004). A adesão foi realizada por snowball sampling (Biernacki e Waldorf, 1981), em que os próprios respondentes indicam novos participantes para compor a amostra. Esse método de amostragem é comumente utilizado quando há dificuldade (ou mesmo impossibilidade) na obtenção de uma amostra aleatória para o estudo em questão. Em nosso caso, o formulário de entrevista foi divulgado em redes sociais on-line e distribuído também via e-mail, além disso, foi solicitado que os participantes compartilhassem a pesquisa em suas redes para a adesão de novos respondentes.

Um pré-teste foi realizado para a validação do questionário. Inicialmente, dez pessoas preencheram o formulário, retornando também algumas observações acerca da percepção e compreensão deste. As observações dos respondentes foram ponderadas e, a partir delas, foram feitas algumas alterações na primeira versão do questionário. Prosseguiu-se então a divulgação de fato da pesquisa que aconteceu no período de 17 a 25 de julho de 2011, resultando em um total de 226 formulários preenchidos. A Tabela 1 apresenta o resumo da caracterização da amostra deste estudo: 
Tabela 1

\section{Caracterização da amostra}

\begin{tabular}{|c|c|c|}
\hline Características & $\mathbf{n}$ & $\%$ \\
\hline \multicolumn{3}{|l|}{ Gênero } \\
\hline Mulheres & 127 & 56 \\
\hline Homens & 99 & 44 \\
\hline \multicolumn{3}{|l|}{ Estado civil } \\
\hline Solteiro(a) & 202 & 89 \\
\hline Casado(a) & 23 & 10,2 \\
\hline Separado(a)/Divorciado(a)/desquitado(a) & 1 & 0,4 \\
\hline \multicolumn{3}{|l|}{ Ocupação } \\
\hline Estudante & 123 & 54 \\
\hline Funcionário com registro CLT & 29 & 12,8 \\
\hline Funcionário público & 26 & 11,5 \\
\hline Profissional liberal & 24 & 10,6 \\
\hline Autônomo & 19 & 8,4 \\
\hline Empresário & 5 & 2,2 \\
\hline \multicolumn{3}{|l|}{ Idade } \\
\hline De 18 e 24 anos & 138 & 61 \\
\hline De 25 e 34 anos & 65 & 29 \\
\hline \multicolumn{3}{|l|}{ Estado de residência } \\
\hline Bahia & 194 & 86 \\
\hline São Paulo & 15 & 6,6 \\
\hline Outros países & 2 & 0,9 \\
\hline Rio de Janeiro & 2 & 0,9 \\
\hline Rio Grande do Sul & 2 & 0,9 \\
\hline Acre & 1 & 0,4 \\
\hline Ceará & 1 & 0,4 \\
\hline Distrito Federal & 1 & 0,4 \\
\hline Espírito Santo & 1 & 0,4 \\
\hline Goiás & 1 & 0,4 \\
\hline Maranhão & 1 & 0,4 \\
\hline Minas Gerais & 1 & 0,4 \\
\hline Paraná & 1 & 0,4 \\
\hline Pernambuco & 1 & 0,4 \\
\hline Piauí & 1 & 0,4 \\
\hline Santa Catarina & 1 & 0,4 \\
\hline \multicolumn{3}{|l|}{ Orientação sexual } \\
\hline Heterossexual & 181 & 80 \\
\hline Homossexual & 25 & 11 \\
\hline Bissexual & 15 & 6,6 \\
\hline Não Sabe & 5 & 2,2 \\
\hline
\end{tabular}




\begin{tabular}{|l|c|c|}
\hline Características & n & $\mathbf{5}$ \\
\hline Religião & & \\
\hline Não tenho & 103 & 45,6 \\
\hline Protestantes & 54 & 23,9 \\
\hline Católicos & 38 & 16,8 \\
\hline Espíritas & 20 & 8,8 \\
\hline Umbanda ou candomblé & 2 & 0,9 \\
\hline Outras religiões & 9 & 4 \\
\hline
\end{tabular}

Fonte: Elaboração própria com base em dados coletados pelo questionário realizado pela autora.

Por conta do formato de aplicação dos questionários, no meio on-line, não se verificou a ocorrência de dados perdidos na pesquisa, visto que a resposta a todas as questões era obrigatória, sendo pré-requisito para a conclusão do envio do formulário.

\section{Hipóteses}

As seguintes hipóteses orientam este estudo:

Hipótese 1: A percepção da exposição da imagem pessoal será negativamente relacionada com a suscetibilidade de expressão da opinião.

Hipótese 2a: O medo de isolamento será negativamente associado com a suscetibilidade de expressão da opinião pessoal.

Hipótese 2b: O efeito do medo de isolamento em relação ao desejo de se expressar irá variar de acordo com as características de cada cenário comunicativo.

Hipótese 3a: A congruência atual da opinião será positivamente relacionada à suscetibilidade de o indivíduo expressar sua opinião.

Hipótese 3b: O efeito da congruência atual da opinião em relação ao desejo de se expressar irá variar de acordo com as características de cada cenário comunicativo.

Hipótese 4a: A congruência futura da opinião será positivamente relacionada à suscetibilidade de o indivíduo expressar sua opinião.

Hipótese 4b: O efeito da congruência futura da opinião em relação ao desejo de se expressar irá variar de acordo com as características de cada cenário comunicativo.

Hipótese 5: Devido à ampla visibilidade proporcionada pelos sites de redes sociais na comunicação contemporânea, os respondentes indicarão menor grau de suscetibilidade em manifestar suas opiniões nesses sites, em comparação com os demais contextos on-line e off-line.

\section{Medidas}

A medida do uso da mídia foi dividida em duas partes. Em um primeiro momento, os participantes responderam a cinco questões, nas quais se solicitou que indicassem a frequência semanal de exposição à mídia. Observou-se um maior uso de jornais on-line, 
seguido de televisão aberta e canais locais de televisão, conforme pode ser verificado na Tabela 2:

Tabela 2

Uso da mídia

\begin{tabular}{|l|c|c|}
\hline Frequência semanal de exposição à mídia & Média & Desvio-padrão \\
\hline Jornais on-line & 4,40 & 2,41 \\
\hline Televisão aberta & 3,74 & 2,57 \\
\hline Canais locais de televisão & 2,62 & 2,53 \\
\hline Canais fechados & 2,08 & 2,59 \\
\hline Jornais impressos & 1,20 & 1,82 \\
\hline
\end{tabular}

Fonte: Elaboração própria com base em dados coletados pelo questionário realizado pela autora.

Depois, solicitou-se aos respondentes que indicassem o grau de atenção que dedicam ao tema união civil entre pessoas do mesmo sexo em veículos midiáticos, que seguiu o mesmo padrão da frequência de exposição, divididos em: jornais on-line, noticiário televisivo e jornais impressos (Tabela 3):

\section{Tabela 3}

\section{Grau de atenção dedicado ao tema união civil entre pessoas do mesmo sexo em veículos midiáticos}

\begin{tabular}{|l|c|}
\hline $\begin{array}{l}\text { Grau de atenção dedicado ao tema união } \\
\text { civil entre pessoas do mesmo sexo em } \\
\text { veículos midiáticos }\end{array}$ & $\begin{array}{l}\text { Maior índice de } \\
\text { atenção em \% }\end{array}$ \\
\hline Jornais on-line & 35 \\
\hline Noticiário televisivo & 33,6 \\
\hline Jornais impressos & 19 \\
\hline
\end{tabular}

Fonte: Elaboração própria com base em dados coletados pelo questionário realizado pela autora.

Para operacionalizar o medo de isolamento, foi desenvolvida uma medida a partir de estudos prévios realizados por Scheufele, Shanahan e Lee (2001) e Ho e McLeod (2008), composta de cinco itens para avaliar emoções positivas e negativas relacionadas à situação de conversação. Nomeadamente, os participantes classificaram o nível de concordância com os cinco itens apresentados. Para tanto, foi utilizada a escala de Likert, com cinco pontos, de 1 (discordo fortemente) a 5 (concordo fortemente), a partir da qual os entrevistados puderam indicar seu grau de concordância ou discordância com relação às seguintes declarações: (a) "Eu me preocupo em ficar isolado se as pessoas não concordam comigo", (b) "Eu evito falar para outras pessoas o que eu penso quando existe um risco de elas me evitarem se souberem minha opinião", (c) "Eu não gosto de entrar em discussões polêmicas", (d) "Discutir sobre temas polêmicos aperfeiçoa minha inteligência", (e) "Eu gosto de uma boa discussão sobre um tema polêmico". Para o cálculo, os itens (d) e (e) foram codificados ao reverso, visto que se trata de declarações 
que descrevem emoções positivas. O medo de isolamento foi identificado para cada indivíduo em que a mediana observada entre as respostas das cinco afirmativas descritas foi maior ou igual a 3. A variável medo de isolamento foi então construída a partir de uma matriz para o filtro entre os indivíduos com medo de isolamento, grupo formado por 61 pessoas na amostra.

Para medir a congruência corrente de opinião, foi solicitado aos participantes que indicassem sua própria posição em relação ao casamento civil entre pessoas do mesmo sexo: $73 \%$ afirmaram ser a favor, $19 \%$ contra e $8 \%$ marcaram a opção "não tenho opinião formada". Os dados foram recodificados para -1 (contra), +1 (a favor) e 0 (não tenho opinião formada). Em um segundo momento, solicitou-se aos respondentes que estimassem, em porcentagem, quantas pessoas, de acordo com a percepção pessoal, concordam com a união civil entre pessoas do mesmo sexo. Essa medida foi composta de quatro questões, nas quais foi requerida a percepção dos entrevistados com relação a sociedade brasileira em geral, seu círculo de convivência fora da internet, sua rede social on-line (Orkut, Facebook, Twitter) e internet de modo geral7. Foi construída então uma tabela de contingência para identificar as respostas compatíveis entre opinião pessoal e percepção do clima de opinião em cada situação observada.

A congruência futura de opinião foi medida a partir da seguinte pergunta: "na sua percepção, qual é a tendência futura da opinião das pessoas em geral, na sociedade brasileira, com relação à concordância com a união civil entre pessoas do mesmo sexo?", com as opções de resposta: (a) irá aumentar, (b) continuará a mesma, (c) irá diminuir. Os dados foram recodificados para 1,0 e -1 . Seguindo o mesmo padrão da medida de congruência corrente, a congruência futura foi identificada a partir da tabela de contingência entre as variáveis opinião pessoal e tendência futura da opinião pública.

\section{Contextos}

Para avaliar as características dos contextos comunicativos, foi solicitado aos respondentes, no questionário, que indicassem o quanto consideram que sua imagem pessoal está exposta nas seguintes situações: no Twitter, no Facebook, no Orkut, em uma sala de bate-papo on-line, em fóruns de discussão on-line e em uma discussão presencial. A medida se deu de acordo com uma escala de 5 pontos, indo de 0 (nenhuma exposição) a 4 (total exposição). Além disso, solicitou-se, por fim, que os participantes classificassem o quanto se sentem à vontade para expressar suas opiniões pessoais a respeito da união entre pessoas do mesmo sexo nos mesmos ambientes especificados na

\footnotetext{
7 Interessante ressaltar que, no que diz respeito à sociedade brasileira em geral, aproximadamente $89 \%$ dos respondentes consideraram a maioria da população como contrária à união civil. Quanto à rede social on-line, $60 \%$ dos entrevistados, aproximadamente, indicaram uma maioria favorável em suas redes. Outro dado é que, no que se refere ao círculo de convivência fora da internet e à rede social on-line, apareceram respostas indicando os extremos ( $0 \%$ ou $100 \%$ ), o que não aconteceu nas outras duas estimativas sociedade brasileira e internet em geral. Isso pode ser explicado, obviamente, pelo fato de os indivíduos se sentirem mais autorizados a julgar as situações nas quais os "outros" estão mais próximos.
} 
questão referida acima, de acordo com uma escala de 0 (não me sinto à vontade) a 4 (totalmente à vontade). Reitera-se aqui que a inclusão dos sites de redes sociais como contexto para este artigo se justifica pelo fato de se configurarem como ambientes de visibilidade no meio on-line, oferecendo, por isso, potencial de coerção à exposição de opiniões pessoais, devido ao risco de sanções sociais ${ }^{8}$.

\section{Resultados e discussão}

A fim de testar as relações hipotéticas, foi aplicada uma análise de regressão logística multinomial para cada um dos contextos em estudo. Os dados foram divididos em seis estratos, cada estrato representando um ambiente de conversação. A variável resposta foi a expressão da opinião, e as variáveis explicativas foram os efeitos de predisposição: medo de isolamento, congruência corrente de opinião, congruência futura de opinião e exposição percebida. Foi conduzido um modelo multinomial para cada contexto separadamente e, depois, foram realizados testes de independência utilizando o teste qui-quadrado de Pearson para cada uma das variáveis explicativas. Como auxílio, a estatística descritiva foi também utilizada para avaliar algumas hipóteses deste artigo.

Em primeiro lugar, verificou-se, de forma geral, que a imagem pessoal foi percebida como mais exposta no contexto de comunicação face a face (Tabela 4). Seguiram-se os sites de redes sociais na seguinte ordem: Facebook, Orkut e Twitter. Quanto a salas de bate-papo e fóruns de discussão on-line, a maior parte dos respodentes considerou esses contextos como ambientes em que não há exposição.

Tabela 4

Quanto você considera que sua imagem/pessoa está exposta? (\%)*

\begin{tabular}{|l|c|c|c|c|c|}
\hline & $\begin{array}{c}\text { Nenhuma } \\
\text { exposição }\end{array}$ & $\begin{array}{c}\text { Pouca } \\
\text { exposição }\end{array}$ & Neutra & $\begin{array}{c}\text { Muita } \\
\text { exposição }\end{array}$ & $\begin{array}{c}\text { Total } \\
\text { exposição }\end{array}$ \\
\hline No Twitter & 12.83 & 18.58 & 25.22 & $\mathbf{2 6 . 5 5}$ & 16.81 \\
\hline No Facebook & 1.77 & 7.96 & 24.34 & $\mathbf{3 6 . 2 8}$ & 29.65 \\
\hline No Orkut & 8.85 & 12.39 & 26.99 & $\mathbf{2 9 . 6 5}$ & 22.12 \\
\hline $\begin{array}{l}\text { Em uma sala de } \\
\text { bate-papo }\end{array}$ & $\mathbf{5 0 . 8 8}$ & 28.32 & 11.95 & 5.31 & 3.54 \\
\hline $\begin{array}{l}\text { Em fóruns de } \\
\text { discussão on-line }\end{array}$ & $\mathbf{3 8 . 9 4}$ & 26.99 & 20.8 & 7.96 & 5.31 \\
\hline $\begin{array}{l}\text { Em uma discussão } \\
\text { presencial }\end{array}$ & 3.1 & 6.64 & 17.7 & 24.78 & $\mathbf{4 7 . 7 9}$ \\
\hline
\end{tabular}

Fonte: Elaboração própria com base em dados coletados pelo questionário realizado pela autora.

* Proporção de respostas para exposição percebida por ambiente.

8 O objetivo foi levar em conta a expressão da opinião de forma geral, independentemente de se tratar de situações de debate. Os sites de redes sociais considerados aqui, por exemplo, nem sempre configuram discussões entre os indivíduos. 
Essa percepção pode ser explicada pelas características próprias de cada ambiente. Como dito anteriormente, a comunicação face a face envolve a utilização de uma grande quantidade de sistemas sígnicos, como o gestual, o vestuário, o tom da voz, prevendo a possibilidade de interpretação da expressão de um indivíduo não apenas por meio daquilo que é falado, mas também através de pistas não verbais. Nos sites de redes sociais, essas propriedades são mais limitadas, mas, ao passo que o indivíduo pode ser representado na rede por meio de um perfil, a presença social é mais complexa. Em plataformas como Facebook existe a possibilidade de criar perfis mais completos, com fotos, vídeos e diversas informações pessoais e profissionais. Quanto a isso, no Twitter as informações que caracterizam cada pessoa são limitadas a uma foto, descrição textual e localização geográfica. Já em fóruns de discussão on-line e salas de bate-papo, geralmente, a comunicação se dá em condição de anonimato, o que pode produzir uma menor sensação de exposição da imagem pessoal. O teste de independência, no entanto, revelou que, para nenhuma das situações analisadas, houve associação entre a exposição percebida e a expressão da opinião, conforme se esperava, não havendo confirmação para a hipótese 1 . Conforme observa-se na Tabela 5, não houve resultado significativo no teste (o valor-p foi aproximadamente 1 para a maioria dos casos):

Tabela 5

Teste qui-quadrado de Pearson para associação entre suscetibilidade de expressão da opinião e exposição percebida

\begin{tabular}{|l|c|c|c|}
\hline & X-squared & df & Valor-p \\
\hline Twitter & 273.61 & 451 & 1 \\
\hline Facebook & 188.67 & 451 & 1 \\
\hline Orkut & 284.23 & 451 & 1 \\
\hline Salas de bate-papo & 434.53 & 451 & 0.703 \\
\hline Fóruns de discussão on-line & 400.59 & 451 & 0.9576 \\
\hline Discussão presencial & 157.39 & 451 & 1 \\
\hline
\end{tabular}

Fonte: Elaboração própria com base em dados coletados pelo questionário realizado pela autora.

Com relação à associação entre o medo de isolamento e a suscetibilidade de expressão da opinião pessoal, aplicamos um modelo multinomial para avaliar a associação entre a escolha de um ambiente para expressão da opinião. Par tanto, comparamos o contexto de discussão presencial em relação a cada um dos contextos online para os casos em que há medo de isolamento. O resultado dos modelos indica que a relação de escolha entre o contexto presencial e qualquer um dos contextos on-line em estudo é bastante parecida em qualquer caso, conforme observa-se na semelhança entre os AICs $^{9}$ indicados na Tabela 6:

${ }^{9}$ O Critério de Informação de Akaike (AIC) é um método de seleção de modelos em modelagem de dados. Ele é utilizado para comparar o ajustamento dos modelos buscando evidências de um modelo que se destaque, a fim de selecionar o melhor entre eles. 
Tabela 6

Suscetibilidade de expressão da opinião pessoal dado que há medo de isolamento. Modelo multinomial para discussão presencial vs. contextos on-line

\begin{tabular}{|l|c|c|}
\hline & df & AIC \\
\hline Presencial vs. Twitter & 20 & 155.6325 \\
\hline Presencial vs. Facebook & 20 & 156.3736 \\
\hline Presencial vs. Orkut & 20 & 159.9092 \\
\hline $\begin{array}{l}\text { Presencial vs. Salas de bate- } \\
\text { papo }\end{array}$ & 20 & 158.2607 \\
\hline $\begin{array}{l}\text { Presencial vs. Fóruns de } \\
\text { discussão on-line }\end{array}$ & 20 & 146.3853 \\
\hline
\end{tabular}

Fonte: Elaboração própria com base em dados coletados pelo questionário realizado pela autora.

Após a aplicação do modelo, foi realizado um teste qui-quadrado para cada um deles a partir do qual verificamos a existência de associação significativa em todos os casos, conforme pode ser observado por cada valor-p indicado na Tabela 7, fixando grau de significância de $5 \%$ :

Tabela 7

Teste qui-quadrado de Pearson para discussão presencial vs. contextos on-line

\begin{tabular}{|l|c|}
\hline & Valor-p \\
\hline Presencial vs. Twitter & $6.306632 \mathrm{e}-06$ \\
\hline Presencial vs. Facebook & $1.501492 \mathrm{e}-05$ \\
\hline Presencial vs. Orkut & $3.106792 \mathrm{e}-06$ \\
\hline Presencial vs. Salas de bate-papo & $4.221411 \mathrm{e}-05$ \\
\hline Presencial vs. Fóruns de discussão on-line & $4.805381 \mathrm{e}-09$ \\
\hline
\end{tabular}

Fonte: Elaboração própria com base em dados coletados pelo questionário realizado pela autora.

Após a verificação da significância do teste de independência, comparamos as associações entre cada um dos ambientes on-line e o contexto presencial em relação à suscetibilidade de expressão da opinião. Como pode ser observado na Tabela 8, em todos os casos, a maior parte das pessoas demonstrou estar mais à vontade para se expressar no ambiente on-line quando também estão em um contexto presencial, indicando que não há uma dissociação tão grande entre o modo como um indivíduo se comporta no meio on-line e seu comportamento em uma comunicação face a face, no que diz respeito à expressão de uma opinião. 


\section{Tabela 8}

Associação entre suscetibilidade de expressão da opinião em discussão presencial e contextos on-line dado que há medo de isolamento

\begin{tabular}{|l|c|c|c|c|c|}
\hline & $\begin{array}{c}\text { Não se } \\
\text { sente à } \\
\text { vontade }\end{array}$ & $\begin{array}{c}\text { Pouco à } \\
\text { vontade }\end{array}$ & Neutro & $\begin{array}{c}\text { Bastante } \\
\text { à } \\
\text { vontade }\end{array}$ & $\begin{array}{c}\text { Totalmente } \\
\text { à vontade }\end{array}$ \\
\hline Twitter & 0.00 & 0.05 & 0.38 & 0.00 & 0.57 \\
\hline Facebook & 0.00 & 0.00 & 0.33 & 0.16 & 0.51 \\
\hline Orkut & 0.07 & 0.08 & 0.34 & 0.05 & 0.46 \\
\hline Bate-papo & 0.07 & 0.00 & 0.36 & 0.00 & 0.57 \\
\hline Fórum & 0.33 & 0.00 & 0.15 & 0.07 & 0.46 \\
\hline
\end{tabular}

Fonte: Elaboração própria com base em dados coletados pelo questionário realizado pela autora.

Tendo em vista todas as características delineadas aqui, as hipóteses $2 a$ e $2 b$ confirmam-se parcialmente.

Com relação à congruência de opiniões, a percepção de congruência futura não teve relação com a variável dependente, portanto, o pressuposto de que a congruência futura da opinião seria positivamente relacionada à suscetibilidade de o indivíduo se expressar não foi confirmado, não dando suporte às hipóteses $4 a$ e 4b. Todos os valores$\mathrm{p}$ indicados na Tabela 9 são próximos a 1:

Tabela 9

Teste qui-quadrado de Pearson para associação entre suscetibilidade de expressão da opinião e congruência futura de opinião para cada ambiente

\begin{tabular}{|l|c|c|c|}
\hline & X-squared & df & Valor-p \\
\hline Twitter & 392.02 & 451 & 0.979 \\
\hline Facebook & 379.03 & 451 & 0.994 \\
\hline Salas de bate-papo & 411.09 & 451 & 0.9111 \\
\hline Fóruns de discussão on-line & 389.61 & 451 & 0.9831 \\
\hline Discussão presencial & 369.7 & 451 & 0.9979 \\
\hline
\end{tabular}

Fonte: Elaboração própria com base em dados coletados pelo questionário realizado pela autora.

No entanto, as percepções de congruência entre a própria opinião e o clima corrente de opinião foram significativamente relacionadas com a suscetibilidade de se expressar, confirmando a hipótese 3a, o que pode ser conferido na Tabela 10. Fixando o grau de significância em 5\%, observa-se que a associação foi significativa, entretanto, apenas considerando a relação entre a própria opinião e o clima de opinião da sociedade brasileira de forma geral, o que sugere que, independentemente do contexto de conversação, a congruência entre a opinião pessoal e a percepção de opinião da sociedade de forma geral é um importante preditor para a suscetibilidade de expressão da opinião, não tendo suporte para a hipótese $3 b$. 
Tabela 10

Teste qui-quadrado de Pearson para associação entre suscetibilidade de expressão da opinião e congruência atual de opinião para cada ambiente em cada situação considerada.

\begin{tabular}{|l|c|c|c|c|}
\hline & $\begin{array}{c}\text { Sociedade } \\
\text { brasileira } \\
\text { em geral }\end{array}$ & $\begin{array}{c}\text { Círculo de } \\
\text { convivência } \\
\text { fora da } \\
\text { internet }\end{array}$ & $\begin{array}{c}\text { Pessoas } \\
\text { em sua } \\
\text { rede social } \\
\text { on-line }\end{array}$ & $\begin{array}{c}\text { Pessoas na } \\
\text { internet de } \\
\text { forma } \\
\text { geral }\end{array}$ \\
\hline Twitter & 0.0076 & 0.8077 & 0.9227 & 0.1579 \\
\hline Facebook & 0.0216 & 0.9078 & 0.9707 & 0.2817 \\
\hline Orkut & 0.0018 & 0.5942 & 0.7784 & 0.0603 \\
\hline Salas de bate-papo & 0.0128 & 0.8379 & 0.9366 & 0.1996 \\
\hline Fóruns de discussão on-line & 0.0315 & 0.9480 & 0.9866 & 0.3598 \\
\hline Discussão presencial & 0.0026 & 0.6733 & 0.8394 & 0.0823 \\
\hline
\end{tabular}

Fonte: Elaboração própria com base em dados coletados pelo questionário realizado pela autora. Significância do teste com 451 graus de liberdade.

Estudos anteriores indicam que a relação entre a percepção do clima de opinião e o desejo de se expressar não é um componente da teoria totalmente confirmado na literatura existente (Glynn, Hayes e Shanahan, 1997). Scheufele, Shanahan e Lee (2001) apontam que pesquisas anteriores sugerem que as percepções da tendência futura da opinião pública podem ser, inclusive, um melhor preditor da expressão da opinião pessoal do que as percepções do clima corrente de opinião. Vale destacar aqui que, em nossa amostra, aproximadamente $85 \%$ dos respondentes perceberam o clima de opinião futuro como favorável à questão do casamento civil entre pessoas do mesmo sexo, enquanto praticamente a mesma porcentagem percebeu o clima atual com no máximo $50 \%$ de aceitação na sociedade brasileira. A hipótese 5 previa que, devido à ampla visibilidade proporcionada pelos sites de redes sociais, os respondentes indicariam menor grau de suscetibilidade em manifestar suas opiniões nesses sites. Em qualquer caso, a hipótese se confirma quando se leva em conta a comparação com o contexto off-line somente (Tabela 11). Dessa forma, a hipótese foi parcialmente confirmada. 
Tabela 11

Quanto você se sente à vontade para expressar sua opinião? (\%)*

\begin{tabular}{|l|c|c|c|c|c|}
\hline & $\begin{array}{c}\text { Não se sente } \\
\text { à vontade }\end{array}$ & $\begin{array}{c}\text { Pouco à } \\
\text { vontade }\end{array}$ & Neutro & $\begin{array}{c}\text { Bastante à } \\
\text { vontade }\end{array}$ & $\begin{array}{c}\text { Totalmente à } \\
\text { vontade }\end{array}$ \\
\hline No Twitter & 17.7 & 7.52 & 10.18 & 15.93 & 48.67 \\
\hline No Facebook & 14.16 & 9.73 & 9.73 & 19.03 & 47.35 \\
\hline No Orkut & 26.11 & 7.08 & 7.52 & 13.72 & 45.58 \\
\hline $\begin{array}{l}\text { Em uma sala de } \\
\text { bate-papo }\end{array}$ & 21.24 & 9.73 & 10.62 & 15.04 & 43.36 \\
\hline $\begin{array}{l}\text { Em fóruns de } \\
\text { discussão } \\
\text { on-line }\end{array}$ & 22.12 & 4.87 & 9.29 & 15.49 & 48.23 \\
\hline $\begin{array}{l}\text { Em uma } \\
\text { discussão } \\
\text { presencial }\end{array}$ & 8.41 & 5.31 & 12.83 & 19.03 & 54.42 \\
\hline
\end{tabular}

Fonte: Elaboração própria com base em dados coletados pelo questionário realizado pela autora.

*Proporção de respostas para suscetibilidade de expressão por ambiente.

\section{Conclusão}

Em conjunto, os resultados deste artigo sugerem que a configuração da comunicação afeta o desejo dos indivíduos em expressar seus pontos de vista, fazendo com que a espiral do silêncio aconteça de forma diferente nos vários cenários comunicativos. De forma específica, entretanto, nem todas as hipóteses levantadas aqui foram completamente confirmadas. De acordo com a análise apresentada, foram confirmadas, total ou parcialmente, as hipóteses $2 a, 2 b$ e $3 a$. A hipótese 5 foi parcialmente confirmada. Já as hipóteses 1 , 3b, 4a e 4b não foram comprovadas.

Assim, como se confirma com as hipóteses $2 \mathrm{a}, 2 \mathrm{~b}$ e $3 \mathrm{a}$, o medo de isolamento é negativamente associado com a suscetibilidade de expressão da opinião pessoal, já a congruência entre a própria opinião e o clima corrente de opinião está positivamente relacionada com a suscetibilidade de se expressar. $\mathrm{O}$ que significa que, quanto maior $\mathrm{o}$ nível do medo de isolamento, menor o desejo de se expressar. A percepção de congruência entre a própria opinião e o clima corrente de opinião, por outro lado, aumenta a suscetibilidade de expressão da opinião.

Em alguns casos, o efeito em relação ao desejo de se expressar varia de acordo com o cenário comunicativo. Para o medo de isolamento, a comparação entre uma discussão presencial e qualquer contexto on-line é bastante similar, o que demonstra que os indivíduos tendem a se sentir mais à vontade para se expressar em um ambiente online, quando também se sentem à vontade em um contexto off-line.

Conforme observado, os respondentes foram, em geral, significativamente mais suscetíveis a expressar sua própria opinião no contexto da discussão presencial em comparação com as outras situações especificadas. A quinta hipótese obteve confirmação parcial. De acordo com o levantado inicialmente, os respondentes indicariam menor grau de suscetibilidade em manifestar suas opiniões em sites de redes sociais, quando 
comparados aos demais contextos on-line e off-line. No entanto, a hipótese se confirmou apenas na comparação entre sites de redes sociais e o contexto off-line.

Não se confirmaram neste artigo as hipóteses 1, 4a e 4b. Não houve associação entre a exposição percebida e a expressão da opinião e não houve associação entre congruência de opinião futura e disposição para se expressar. É importante destacar, portanto, que a projeção que as pessoas fazem do cenário atual é mais importante do que a avaliação que fazem da tendência do clima de opinião. Os respondentes que perceberam suas opiniões como coerentes com o clima de opinião foram mais inclinados a declarar sua própria opinião. Já a congruência futura não foi um preditor para a expressão.

Com relação à influência da projeção do clima de opinião, é fundamental pontuar a importância do contexto social em que o tema se insere. Os dados coletados para este artigo foram adquiridos de questionários aplicados dois meses após o reconhecimento constitucional do STF da união estável entre casais do mesmo sexo como entidade familiar, em 2011. Esse cenário gerou, possivelmente, uma projeção da avaliação de um aumento da concordância social em relação ao tema. O mesmo questionário, aplicado em contexto espaço-temporal diferente, pode gerar uma percepção do clima corrente ou futuro de opinião divergente, ainda que isso continue implicando no modo como as pessoas avaliam a congruência entre as opiniões (individual e coletiva) e o impacto disso na disposição de expressar sua própria opinião em contexto desfavorável.

Este artigo, portanto, traz um resultado importante no que diz respeito à compreensão da influência de fatores externos aos pressupostos da teoria da espiral do silêncio, confrontando o resultado de pesquisas anteriores (McDevitt, Kiousis e WhalJorgensen, 2003; Ho e McLeod, 2008), que sugerem que as discussões mediadas por computador podem aliviar a hesitação daqueles que pertencem ao grupo minoritário, conduzindo a debates mais vigorosos do que os que ocorrem na comunicação face a face. Ao contrário, os dados apresentados demonstram que, em vários contextos dentro do ambiente on-line, os indivíduos tendem a se sentir menos à vontade para expressar uma opinião quando percebem que ela é minoritária. A premissa de que o meio on-line proporciona um ambiente mais tranquilo para o debate é contestada aqui, visto que, conforme demonstrado neste artigo, os efeitos que atuam na espiral do silêncio, ainda que possam ser atenuados em certos espaços, são potencializados em outros, diminuindo a suscetibilidade de um indivíduo se expressar em alguns ambientes no meio on-line.

Uma questão metodológica que precisa ser destacada é a utilização de survey para cenários hipotéticos. Nesse método de pesquisa, a verificação se baseia nas respostas do questionário e não na ação efetiva dos indivíduos. Pesquisas futuras poderão procurar esses resultados em discussões reais ou, ainda, analisar cada cenário separadamente. Dessa forma, além da possibilidade de observar as participações reais e o desejo de expressar opiniões de forma imediata, os pesquisadores poderão examinar 
outros fatores e mecanismos subjacentes à expressão de opinião, como a qualidade do argumento, por exemplo (Ho e McLeod, 2008).

Após a análise dos dados apresentados, retornamos à reflexão teórica na tentativa de compreender a interseção entre a configuração do contexto em que as trocas comunicativas acontecem e os pressupostos da teoria da espiral do silêncio (Noelle-Neumann, 1974). Em primeiro lugar, entendemos que a configuração da comunicação afeta o desejo dos indivíduos em expressar seus pontos de vista, fazendo com que a espiral do silêncio aconteça de forma diferente nos vários contextos comunicativos. Essa configuração considera não apenas a mediação tecnológica, mas todos os aspectos contextuais que envolvem o processo comunicativo - como o número de pessoas que participam da interação, quem são essas pessoas, o quão visível a fala se tornará uma vez tornada pública etc.

A expressão da opinião, portanto, parece estar ligada às características específicas de cada meio, em conjunto com os efeitos dos fatores sociopsicológicos que operam na espiral do silêncio. Assim, este artigo contribui para uma melhor compreensão do impacto da mediação tecnológica na expressão da opinião, apontando para a importância de avaliar a extensão na qual os contextos comunicativos afetam a vontade dos indivíduos em expressar suas opiniões, considerando as características contextuais e diferenças de cada cenário no meio on-line e off-line.

\section{Referências bibliográficas}

BALDASSARE, M.; KATZ, C. "Measures of attitude strength as predictors of willingness to speak to the media". Journalism and Mass Communication Quarterly, vol. 73, n 1, p. 147-158, 1996.

BARBER, B. R.; MATTSON, K.; PETERSON, J. The state of "electronically enhanced democracy": a survey of the internet. New Brunswick: Walt Whitman Center, 1997.

BIERNACKI, P.; WALDORF, D. "Snowball sampling: problems and techniques of chain referral sampling". Sociological Methods \& Research, vol. 10, n² 2, p. 141-163, 1981.

BINDER, A., et al. "The soul of a polarized democracy: testing theoretical linkages between talk and attitude extremity during the 2004 presidential election". Communication Research, vol. 36, n 3, p. 315-340, 2009.

CHRISTEN, C.; GUNTHER, A. C. "The influence of mass media and other culprits on the projection of personal opinion". Communication Research, vol. 30, n 4, p. 414-431, 2003.

Davison, W. P. "The third-person effect in communication". Public Opinion Quarterly, vol. 47, $\mathrm{n}^{\circ} 1$, p. $1-15,1983$.

DUCK, J.; HOGG, M.; THERRY, D. "Social identity and perceptions of media persuasion: are we always less influenced than others?". Journal of Applied Social Psychology, vol. 29, n 9, p. 1.879-1.899, 1999.

EVELAND, W.; MCLEOD, D.; SGNORIELLI, N. "Actual and perceived U.S. public opinion: the spiral of silence during the Persian Gulf War". International Journal of Public Opinion Research, vol. 7, n 2, p. 91-109, 1995. 
GLYNN, C.; HAYES, A.; SHANAHAN, J. "Perceived support for one's opinions and willingness to speak out: a meta-analysis of survey studies on the 'spiral of silence'". Public Opinion Quarterly, vol. 61, p. 452-463, 1997.

GoMES, W.; BARRos, S. Influência da mídia, distância moral e desacordos sociais: um teste do efeito de terceira pessoa. In: FrAnÇA, V. V.; ALDÉ, A.; RAMOS, M. C. (eds.). Teorias da comunicação no Brasil. Salvador: Edufba, 2014.

GUNTHER, A. "The persuasive press inference: effects of mass media on perceived public opinion". Communication Research, vol. 25, n5, p. 486-504, 1998.

Gunther, A.; CHIA, S. "Predicting pluralistic ignorance: the hostile media perception and its consequences". Journalism and Mass Communication Quarterly, vol. 78, n 4, p. 688-701, 2001.

HAYES, A.; SHANAHAN, J.; GlynN, C. "Willingness to express one's opinion in a realistic situation as a function of perceived support for that opinion". International Journal of Public Opinion Research, vol. $13, \mathrm{n}^{\circ} 1$, p. $45-58,2001$.

Ho, S.; MCLEOD, D. "Social-psychological influences on opinion expression in face-to-face and computer-mediated communication". Communication Research, vol. 35, n² 2, p. 190-207, 2008.

LASORSA, D. L. "Political outspokenness: factors working against the spiral of silence". Journalism Quarterly, vol. 68, p. 131-139, 1991.

LEVIN, J.; FoX, J. A. Estatística para ciências humanas, 2004.

LIN, W. K.; PFAU, M. "Can inoculation work against the spiral of silence? A case study of public opinion on the future of Taiwan". International Journal of Public Opinion Research, vol. 19, n 2, p. $155-172,2001$.

LONDON, S. Electronic democracy. Dayton: Kettering Foundation, 1993.

MARKS, G.; MILLER, N. "Ten years of research on the false-consensus effect: an empirical and theoretical review". Psychological Bulletin, vol. 41, n 1, p. 72-90, 1987.

McCombs, M.; SHAW, D. L. "The agenda-setting function of mass media". The Public Opinion Quarterly, vol. 36, n², p. 176-187, 1972.

MCDEVITT, M.; KIOUSIS, S.; WhAL-JORGENSEN, K. "Spiral of moderation: opinion expression in computer-mediated discussion". International Journal of Public Opinion Research, vol. 15, $\mathrm{n}^{\circ} 4$, $\mathrm{p}$. 454-470, 2003.

MoY, P.; DOMKE, D.; STAMM, K. "The spiral of silence and public opinion on affirmative action". Journalism and Mass Communication Quarterly, vol. 78, $\mathrm{n}^{\circ}$ 1, p. 7-25, 2001.

NEUWIRTH, K. "Testing the spiral of silence model: the case of Mexico". International Journal of Public Opinion Research, vol. 12, n², p. 138-159, 2000.

NeUWirth, K.; Frederik, E.; MAYo, C. "The spiral of silence and fear of isolation". Journal of Communication, vol. 57, p. 450-468, 2007.

Noelle-NeumanN, E. "The spiral of silence: a theory of public opinion". Journal of Communication, vol. $24, \mathrm{n}^{\circ} 2$, p. 43-51, 1974.

O'ReILly, T. "What is web 2.0: design patterns and business models for the next generation of software", 2005. Disponível em: <https://www.oreilly.com/pub/a/web2/archive/what-is-web20.html>. Acesso em: 15 mar. 2019.

PAN, Z. D., et al. "Mobilizing political talk in a presidential campaign: an examination of campaign effects in a deliberative framework". Communication Research, vol. 33, n 5, p. 315-345, 2006.

PERLOFF, R. "The third person effect: a critical review and synthesis". Media Psychology, vol. 1, n 4, p. 353-378, 1999. 
Petrič, G.; PInTer, A. "From social perception to public expression of opinion: a structural equation modeling approach to the spiral of silence". International Journal of Public Opinion Research, vol. 14, $\mathrm{n}^{\circ} 1$, p. 37-53, 2002.

ReCUero, R. Redes sociais na internet. Porto Alegre: Sulina, 2009.

Rossetto, G. P. N. "Fazendo política no Twitter: como os efeitos estimados das mensagens influenciam as ações e os usos da plataforma". Comunicação e cultura contemporâneas: Tese de Doutorado. Universidade Federal da Bahia, Salvador, 2013.

Salmon, C. T.; NeuWirTh, K. "Perceptions of opinion 'climates' and willingness to discuss the issue of abortion". Journalism Quarterly, vol. 67, n³, p. 567-577, 1990.

SCHEUfELE, D. A. "Deliberation or dispute? An exploratory study examining dimensions of public opinion expression". International Journal of Public Opinion Research, vol. 12, p. 3-28, 1999.

SCheufele, D. A.; MoY, P. "Twenty-five years of the spiral of silence: a conceptual review and empirical outlook". International Journal of Public Opinion Research, vol. 12, n 1, p. 3-28, 2000.

SCheufele, D. A.; ShANAhAN, J.; LEe, E. "Real talk: manipulating the dependent variable in spiral of silence research". Communication Research, vol. 28, n³, p. 304-324, 2001.

Thompson, J. B. A mídia e a modernidade: uma teoria social da mídia. Petrópolis: Vozes, 1998.

Willnat, L.; LeE, W.; Detenber, B. H. "Individual-level predictors of public outspokenness: a test of the spiral of silence theory in Singapore". International Journal of Public Opinion Research, vol. 14, $n^{\circ} 4$, p. 391-412, 2002. 


\section{Anexo}

\section{Questionário}

Olá, participante,

Este questionário faz parte de uma pesquisa sobre mídia e união civil entre pessoas do mesmo sexo. A pesquisa é realizada no interior do Programa de Pós-Graduação em Comunicação e Cultura Contemporâneas da Universidade Federal da Bahia (PósCom/UFBA).

O tempo estimado para responder o questionário é de 5 minutos. Desde já, agradecemos sua colaboração.

TODOS OS DADOS OBTIDOS POR MEIO DESTE QUESTIONÁRIO SÃO CONFIDENCIAIS.

*Obrigatório

Idade*

0-17 anos

18-24 anos

25-34 anos

35-49 anos

50-64 anos

65 anos ou mais

Sexo*

feminino

masculino

Estado civil*

solteiro(a)

casado(a)

separado(a)/divorciado(a)/desquitado(a)

viúvo(a)

Renda familiar em R\$*

545,00 ou menos

entre 545,00 e $1.635,00$

entre $1.635,00$ e $3.270,00$

entre $3.270,00$ e $4.905,00$

mais de $4.905,00$

Número de pessoas no núcleo familiar*

(Contando com seus pais, irmãos ou outras pessoas que moram em uma mesma casa)

Duas pessoas

Três

Quatro

Cinco 


\author{
Mais de seis \\ Moro sozinho(a) \\ Escolaridade* \\ sem estudo escolar \\ ensino fundamental incompleto \\ ensino fundamental completo \\ ensino médio incompleto \\ ensino médio completo \\ ensino superior incompleto \\ ensino superior completo \\ Vínculo empregatício* \\ aposentado/pensionista \\ autônomo \\ empresário \\ estudante \\ funcionário público \\ funcionário com registro CLT \\ profissional liberal
}

Onde reside*

Escolher

Quantos dias na semana passada você assistiu a TV aberta?*

$\begin{array}{llllllll}0 & 1 & 2 & 3 & 4 & 5 & 6 & 7 \\ \bigcirc & \bigcirc & \bigcirc & \bigcirc & \bigcirc & \bigcirc & \bigcirc & \bigcirc\end{array}$

Quantos dias na semana passada você assistiu a TV fechada?*

$\begin{array}{llllllll}0 & 1 & 2 & 3 & 4 & 5 & 6 & 7 \\ \bigcirc & \bigcirc & \bigcirc & \bigcirc & \bigcirc & \bigcirc & \bigcirc & \bigcirc\end{array}$

Quantos dias na semana passada você assistiu a TVs locais?*

$\begin{array}{llllllll}0 & 1 & 2 & 3 & 4 & 5 & 6 & 7 \\ \bigcirc & \bigcirc & \bigcirc & \bigcirc & \bigcirc & \bigcirc & \bigcirc & \bigcirc\end{array}$

Quantos dias na semana passada você leu jornais impressos?* 
OPINIÃO E CENÁRIOS COMUNICATIVOS

$\begin{array}{llllllll}0 & 1 & 2 & 3 & 4 & 5 & 6 & 7 \\ \bigcirc & \bigcirc & \bigcirc & \bigcirc & \bigcirc & \bigcirc & \bigcirc & \bigcirc\end{array}$

Quantos dias na semana passada você leu jornais on-line?*

$\begin{array}{llllllll}0 & 1 & 2 & 3 & 4 & 5 & 6 & 7 \\ \bigcirc & \bigcirc & \bigcirc & \bigcirc & \bigcirc & \bigcirc & \bigcirc & \bigcirc\end{array}$

Classifique os itens abaixo em uma escala de 1 (discordo fortemente) a 5 (concordo fortemente) de acordo com seu nível de concordância com relação às afirmativas.*

$\begin{aligned} & \text { Eu me preocupo } \\ & \text { em ficar isolado } \\ & \text { se as pessoas } \\ & \text { não concordam } \\ & \text { comigo. }\end{aligned}$
$\begin{aligned} & \text { Eu evito falar } \\ & \text { para outras } \\ & \text { pessoas o que } \\ & \text { eu penso } \\ & \text { quando existe } \\ & \text { um risco de elas } \\ & \text { me evitarem se } \\ & \text { souberem } \\ & \text { minha opinião. }\end{aligned}$

Dos itens abaixo, marque aqueles que você utiliza:*

Twitter

Facebook

Orkut

Sala de bate-papo (ex. bate-papo UOL, Terra Chat etc.)

Fóruns de discussão on-line 
Classifique o quanto você considera que a sua imagem/pessoa está exposta nas seguintes situações, de acordo com uma escala de 0 (nenhuma exposição) a 4 (total exposição)*

(Mesmo que você não seja usuário dessas ferramentas, estime o quanto estaria exposto caso utilizasse)

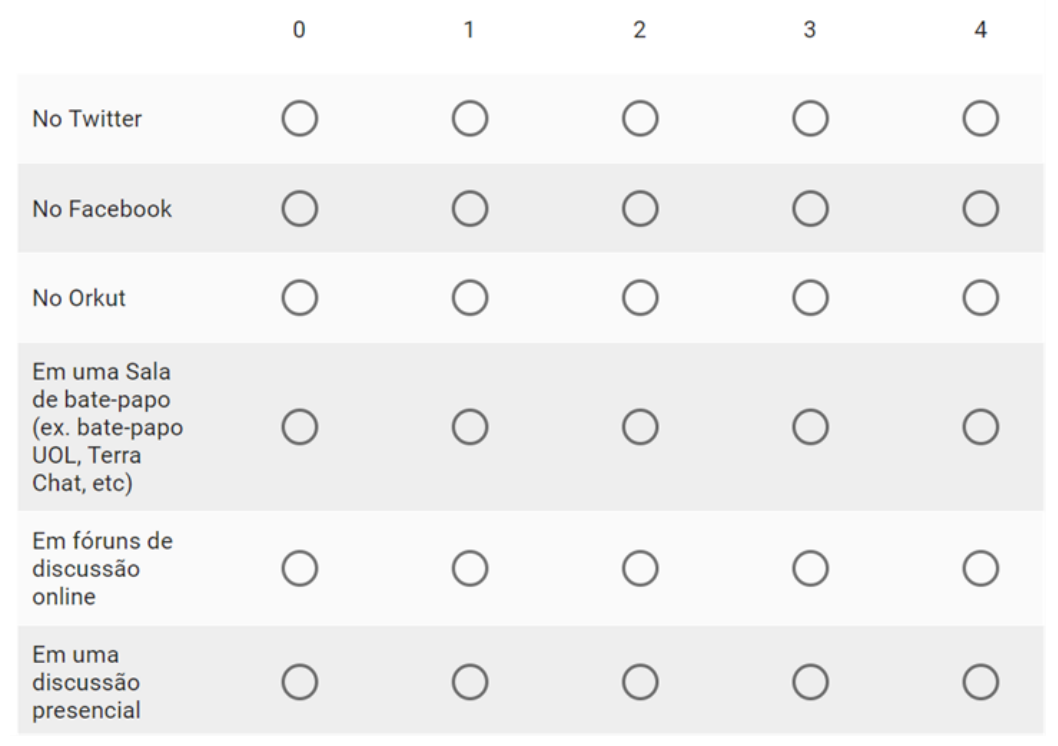

De 0 a 4, indique o grau de atenção que você dedica ao tema união civil entre pessoas do mesmo sexo, em jornais impressos.*
0
1
2
3
4

De 0 a 4, indique o grau de atenção que você dedica ao tema união civil entre pessoas do mesmo sexo, em jornais on-line.*

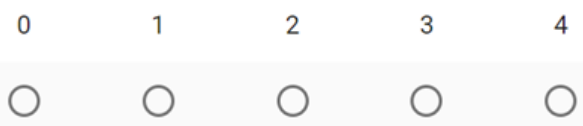

De 0 a 4, indique o grau de atenção que você dedica ao tema união civil entre pessoas do mesmo sexo, no noticiário televisivo.*
0
1
2
3
4

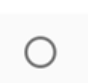
$\bigcirc$
$\bigcirc$

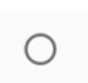

Qual a sua opinião a respeito da regulamentação da união civil entre pessoas do mesmo sexo?* 
OPINIÃO E CENÁRIOS COMUNICATIVOS

Sou contra

Sou a favor

Não tenho opinião formada

De acordo com a sua percepção, indique, em porcentagem, quantas pessoas na sociedade brasileira em geral concordam com a união civil entre pessoas do mesmo sexo.*

$0 \%$

de $1 \%$ a $25 \%$

de $26 \%$ a $50 \%$

de $51 \%$ a $75 \%$

de $76 \%$ a $99 \%$

$100 \%$

De acordo com a sua percepção, indique, em porcentagem, quantas pessoas do seu círculo de convivência fora da internet concordam com a união civil entre pessoas do mesmo sexo.*

$0 \%$

de $1 \%$ a $25 \%$

de $26 \%$ a $50 \%$

de $51 \%$ a $75 \%$

de $76 \%$ a $99 \%$

$100 \%$

De acordo com a sua percepção, indique, em porcentagem, quantas pessoas da sua rede social online (Orkut, Facebook, Twitter) concordam com a união civil entre pessoas do mesmo sexo.*

$0 \%$

de $1 \%$ a $25 \%$

de $26 \%$ a $50 \%$

de $51 \%$ a $75 \%$

de $76 \%$ a $99 \%$

$100 \%$

De acordo com a sua percepção, indique, em porcentagem, quantas pessoas na internet, de modo geral, concordam com a união civil entre pessoas do mesmo sexo.*

$0 \%$

de $1 \%$ a $25 \%$

de $26 \%$ a $50 \%$

de $51 \%$ a $75 \%$

de $76 \%$ a $99 \%$

$100 \%$

Na sua percepção, qual é a tendência futura da opinião das pessoas em geral, na sociedade brasileira, com relação à concordância com a união civil entre pessoas do mesmo sexo?*

irá aumentar

continuará a mesma

irá diminuir 
Classifique o quanto você se sente à vontade para expressar sua opinião a respeito da união entre pessoas do mesmo sexo nas seguintes situações, de acordo com uma escala de 0 (não me sinto a vontade) a 4 (totalmente a vontade). *

(Mesmo que você não seja usuário dessas ferramentas, estime o quanto se sentiria a vontade para expressar sua opinião caso utilizasse)

\begin{tabular}{|c|c|c|c|c|c|}
\hline & 0 & 1 & 2 & 3 & 4 \\
\hline No Twitter & 0 & 0 & $\bigcirc$ & 0 & $\bigcirc$ \\
\hline No Facebook & 0 & 0 & 0 & 0 & 0 \\
\hline No Orkut & 0 & 0 & 0 & 0 & 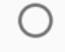 \\
\hline $\begin{array}{l}\text { Em uma Sala } \\
\text { de bate-papo } \\
\text { (ex. bate-papo } \\
\text { UOL, Terra } \\
\text { Chat, etc) }\end{array}$ & 0 & 0 & $\bigcirc$ & 0 & $\bigcirc$ \\
\hline $\begin{array}{l}\text { Em fóruns de } \\
\text { discussão } \\
\text { online }\end{array}$ & 0 & 0 & $\bigcirc$ & 0 & $\bigcirc$ \\
\hline $\begin{array}{l}\text { Em uma } \\
\text { discussão } \\
\text { presencial }\end{array}$ & 0 & 0 & 0 & 0 & 0 \\
\hline
\end{tabular}

Orientação sexual*

Homossexual

Heterossexual

Bissexual

Não sabe

Qual a sua religião?*

Católica

Protestante ou Evangélica

Espírita

Umbanda ou Candomblé

Outra

Sem religião

\section{Abstract}

Opinion and communicative scenarios: influence of contextual factors on the sociopsychological processes of the spiral of silence

This study aims to investigate how contextual factors can affect the socio-psychological processes specified by the Spiral of Silence theory, such as the fear of isolation and opinion congruency. The contexts for this research were divided into online environments-social networking sites (Twitter, Facebook, and Orkut), chat rooms, and online discussion forums-and face-to-face communication. Data were obtained through an online survey about civil union between same-sex couples. Based on 226 completed forms, the data collected were then subject to statistical treatment to test our hypotheses. The analysis of the data revealed that expression of opinion, in association with socio- 
psychological factors that operate in the spiral of silence, is linked to a set of factors related to the specific characteristics of each environment in which the opinion is expressed. Thus, the communication configuration affects individuals' willingness to express their views, so the spiral of silence occurs differently in each context.

Keywords: opinion; spiral of silence; computer-mediated communication; civil union between samesex couples; communicative contexts

\section{Resumen}

Opinión y escenarios comunicativos: influencia de factores contextuales en los procesos sociopsicológicos de la espiral del silencio

El objetivo de este artículo es investigar cómo los factores contextuales pueden afectar los procesos sociopsicológicos especificados por la teoría de la espiral del silencio, como el miedo al aislamiento y la congruencia de opinión. Los contextos se dividieron en entornos en línea (sitios de redes sociales, salas de chat y foros de discusión en línea) y comunicación cara a cara. Los datos se obtuvieron a partir de la aplicación de cuestionarios en línea sobre la unión civil entre personas del mismo sexo. Con un total de 226 formularios rellenados, los datos recolectados recibieron tratamiento estadístico para la realización del test de las hipótesis. El análisis de los datos demostró que la expresión de la opinión está ligada a factores que se relacionan con las características específicas de cada ambiente en que la opinión se expresa en conjunto con los factores sociopsicológicos que operan en la espiral del silencio. Es decir, la configuración de la comunicación afecta el deseo de los individuos en expresar sus puntos de vista, haciendo que la espiral del silencio suceda de forma diferente en cada contexto específico.

Palabras clave: opinión; espiral del silencio; comunicación mediada por ordenador; unión civil homosexual; contextos comunicativos

\section{Résumé}

Scénarios communicatifs et opinion: influence des facteurs contextuels dans les processus sociopsychologiques de la spirale du silence

Cet article vise à étudier comment les facteurs contextuels peuvent influer sur les processus sociopsychologiques spécifiés par la théorie de la spirale du silence, tels que la peur de l'isolement et la congruence de l'opinion. Les contextes ont été divisés en environnements en ligne (sites de réseaux sociaux, salons de discussion et forums de discussion en ligne) et en communication en face à face. Les données ont été obtenues à partir de l'application de questionnaires en ligne sur l'union civile entre personnes du même sexe. Avec un total de 226 formulaires remplis, les données collectées ont reçu un traitement statistique pour effectuer le test d'hypothèse. L'analyse des données a montré que l'expression d'opinion est liée à des facteurs liés aux caractéristiques spécifiques de chaque environnement dans lequel l'opinion est exprimée, ainsi qu'aux facteurs sociopsychologiques qui opèrent dans la spirale du silence. En d'autres termes, la configuration de la communication affecte le désir des individus d'exprimer leurs points de vue, créant ainsi une spirale du silence qui agit différemment selon chaque contexte spécifique.

Mots-clés: opinion; spirale du silence; communication par ordinateur; union civile homosexuelle; contextes de communication

Artigo submetido à publicação em 12 de junho de 2018. Versão final aprovada em 2 de agosto de 2019.

Opinião Pública adota a licença Creative Commons CC-BY. 